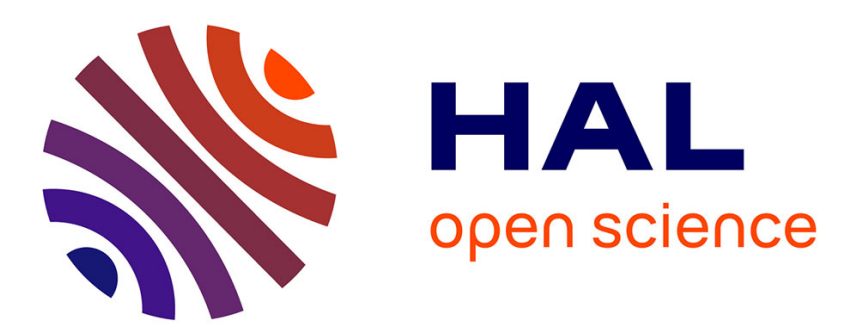

\title{
Specialized microbiome of the cave-dwelling sponge Plakina kanaky (Porifera, Homoscleromorpha)
}

Cesar Ruiz, Marcela Villegas-Plazas, Olivier Thomas, Howard Junca, Thierry Perez

\section{- To cite this version: \\ Cesar Ruiz, Marcela Villegas-Plazas, Olivier Thomas, Howard Junca, Thierry Perez. Specialized microbiome of the cave-dwelling sponge Plakina kanaky (Porifera, Homoscleromorpha). FEMS Mi- crobiology Ecology, 2020, 96 (4), pp.fiaa043. 10.1093/femsec/fiaa043 . hal-02545390}

\section{HAL Id: hal-02545390 \\ https://hal-amu.archives-ouvertes.fr/hal-02545390}

Submitted on 20 Apr 2021

HAL is a multi-disciplinary open access archive for the deposit and dissemination of scientific research documents, whether they are published or not. The documents may come from teaching and research institutions in France or abroad, or from public or private research centers.
L'archive ouverte pluridisciplinaire HAL, est destinée au dépôt et à la diffusion de documents scientifiques de niveau recherche, publiés ou non, émanant des établissements d'enseignement et de recherche français ou étrangers, des laboratoires publics ou privés. 


\section{Specialized microbiome of the cave-dwelling sponge Plakina kanaky (Porifera, Homoscleromorpha)}

César Ruiz ${ }^{1 \#}$, Marcela Villegas-Plazas ${ }^{2 \#}$, Olivier P. Thomas ${ }^{3}$, Howard Junca ${ }^{2}$, Thierry Pérez ${ }^{1 *}$

${ }^{1}$ Institut Méditerranéen de Biodiversité et d’Ecologie Marine et Continentale, UMR 7263 CNRS, Aix Marseille Université, IRD, Avignon Université, Station Marine d’Endoume, Rue Batterie des Lions, 13007, Marseille, France.

${ }^{2}$ RG Microbial Ecology: Metabolism, Genomics \& Evolution; Div Ecogenomics \& Holobionts | Microbiomas Foundation, 250008, Chía-Colombia.

${ }^{3}$ Marine Biodiscovery, School of Chemistry and Ryan Institute, National University of Ireland Galway (NUI Galway), University Road, H91 TK33 Galway, Ireland.

\# These authors contributed equally to this work

\section{Summary}

The recent description of the polychromatic sponge Plakina kanaky revealed original microsymbionts, with some morphotypes recorded for the first time in Homoscleromorpha, and others never before observed in other sponge groups. Illumina 16S amplicon sequencing was used to characterize this microbial community by comparing contents of seven specimens of this Plakinidae with five other sponge species: 1 Homoscleromopha of the Oscarellidae family and 4 Demospongiae. A total of 256,458 sequences of the hypervariable V5-V6 region of the 16S rRNA gene were clustered into 2,829 OTUs at $97 \%$ similarity, with Proteobacteria, Poribacteria and Chloroflexi being the most abundant phyla. The Plakina kanaky specific community appeared to be mainly composed by 5 OTUs representing about $10 \%$ of the total microbiome. Among these, the filamentous bacterium Candidatus Entotheonella, which was among the dominant morphotypes previously observed in the mesohyl and the larvae of $P$. kanaky, was detected in all studied specimens. However, other original and dominant morphotypes could not be assigned to a known prokaryotic taxon. This cave dwelling sponge species harbors a distinctive microbiome composition of potential taxonomic and metabolic novelties that may be linked to its ecological success in such extreme environments.

Keywords: Microbiome, Entotheonella sp, vertical transmission, species-specific community

* Corresponding author: Thierry Pérez, Institut Méditerranéen de Biodiversité et d’Ecologie Marine et Continentale, Station Marine d'Endoume, Rue Batterie des Lions, 13007, Marseille, France. thierry.perez@imbe.fr 


\section{Introduction}

Sponges (Phylum Porifera) are well known marine sessile organisms living in close association with symbiotic Bacteria, Archaea and unicellular Eukaryotes. The microbial communities of these holobionts are often complex in terms of diversity and biotic interactions (Thomas et al. 2016). Transmission electron microscopy has allowed the description of a great variety of microbial morphotypes that can be found in the sponge mesohyl, inside specialized cells and even inside their nuclei. In some sponge species, known as bacteriosponges or High Microbial Abundance (HMA) sponges, the microbial part of the holobiont can constitute up to $40 \%$ of the total biomass represented by a diverse microbial community (Vacelet, 1975; Webster and Taylor 2011; Hardoim et al. 2012; Uriz et al. 2012). It is well accepted that sponge-associated communities are therefore a significant source of unique microbial diversity (Hentschel et al. 2002; Taylor et al. 2007; Thomas et al. 2010; Reveillaud et al. 2014). Sponges harbor rather species-specific prokaryotic communities, composed both by generalist and specialist microbes (Easson and Thacker 2014; Thomas et al. 2016). The rate of host specificity depends on the modes of symbiont transmission, which can be horizontal (from the environment), vertical (through reproduction) or a mixture of both (for a review see Thacker and Freeman 2012). To identify processes of vertical transmission, the symbionts transmitted from parents to offspring can be distinguished using microscopic techniques or traced using molecular tools within the larvae. These associations are often assumed to represent the composite result of co-evolutionary processes, which thus shape the microbiome diversity, influenced by the host specificity and the network of metabolic interactions within the holobiont (Thomas et al. 2010; Pita et al. 2018).

Recent advances in next generation sequencing technologies have led to important progress in the study of microorganisms in their natural environments, surpassing some of the limitations of culture-based methodologies, and revealing new insights into sponge symbiotic diversity and functions (Schmitt et al. 2011; Hentschel et al. 2012). For instance, the retrieval of 16S rRNA gene sequences from metagenomic DNA revealed 52 microbial phyla associated with sponges (Webster and Thomas, 2016), the most common of which

are Proteobacteria, Actinobacteria, Chloroflexi, Bacteroidetes, Acidobacteria, Cyanobacteria, Firmicutes and the candidate phylum Poribacteria. The Archaea lineages Crenarchaeota and Euryachaeota are also well represented (Fieseler et al. 2004; Taylor et al. 2007; Webster et al. 2010; Thomas et al. 2016).

Among Porifera, Homoscleromorpha is the smallest class, currently composed of 124 valid species distributed within two families, Oscarellidae and Plakinidae, and nine genera (Van Soest et al. 2020). Sponges of this group often inhabit semi-dark or dark habitats such as overhangs or submarine caves in shallow waters. The current knowledge of the symbiotic microorganisms of this group is mostly based on electron microscopy observations, with molecular studies enabling a better assessment of the microbial diversity remaining scarce (Gloeckner et al. 2013). The most recent cytological descriptions of various species have revealed dense microbial communities in which the dominant prokaryotic morphotypes are often used as diagnostic traits for the challenging taxonomy of this sponge group. Oscarellidae are mostly LMA sponges, while Plakinidae are generally HMA sponges (Boury-Esnault, Muricy and Gallissian 1995; Muricy et al. 1996, 1999; Gloeckner et al. 2013; Pérez and Ruiz 2018).

Plakina kanaky (Ruiz et al. 2015) is an HMA polychromatic Homoscleromorpha sponge recently described in New Caledonia and harboring an original prokaryotic community, containing, among other morphotypes, a globulous shape never before observed in any Porifera, as well as a filamentous morphology recorded for the first time in 
Homoscleromorpha (Ruiz et al. 2015). TEM observations indicated a common microbial symbiotic community among the various specimens collected, with only subtle variations suspected to be related to sponge chromotypes. The vertical transmission of the two main morphotypes has also been proposed after their observation inside the coeloblastula larva of $P$. kanaky (see Ruiz et al. 2015 and Fig 1). This study aims to characterize the prokaryote community associated with $P$. kanaky, combining the previous morphological description with molecular analyses of the $16 \mathrm{~S}$ rRNA gene amplicon sequencing in order to: 1 ) define the patterns of ribotypes detected in $P$. kanaky individuals compared to other reported sponge microbiomes in the present study; 2) determine if part of the microbial community of $P$. kanaky is species-specific as a first step towards the identification of the original morphotypes previously observed; and 3) define the putative mode of transmission of the microbial taxa representatives deduced from Operational Taxonomic Units (OTUs) and their reported lifestyles.

\section{[FIG 1]}

\section{Material and Methods}

\section{Sponge collection and preservation}

Seven specimens of P. kanaky were collected in November 2010 and February 2013 by scuba diving in New Caledonia (Tropical Southwestern Pacific Ocean), at Bourail

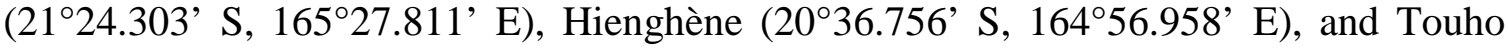
( $20^{\circ} 45.503^{\prime}$ S, $165^{\circ} 16.964^{\prime} \mathrm{E}$ ), in small dark cavities located between 15 and $25 \mathrm{~m}$ depth along the outer slope of the reef (Table 1). These samples were also used for the description of the new species (Ruiz et al. 2015). For molecular analyses, specimens were preserved in ethanol 95\%. For comparative and outgroup purposes, we determined the microbial composition using the same approach of four sponge species (one specimen per species): Amphimedon compressa, Aplysina cavernicola, Petrosia ficiformis (Demospongiae) and Oscarella balibaloi (Homoscleromorpha).

\section{[TABLE 1]}

\section{Metagenomic DNA extraction, 16S rRNA gene library construction and sequencing}

Total DNA extraction from a small $\left(2 \mathrm{~cm}^{3}\right)$ fragment of sponge was performed using a FastDNA ${ }^{\text {TM }}$ SPIN KIT (MP Biomedicals). PCR amplicons of the hypervariable V5-V6 region of the $16 \mathrm{~S}$ rRNA genes were obtained from sponge metagenomic DNA as a template using the primers 807F [5'-GGATTAGATACCCBRGTAGTC- 3'] and 1050R [5'AGYTGDCGACRRCCRTGCA-3'] (Bohorquez et al. 2012). The PCR cycle conditions and Illumina library preparations were performed as previously described ((Milici et al. 2016; Villegas-Plazas et al. 2019) .

\section{Bioinformatics analysis}

All sequence analyses were performed using QIIME 1.9.0 (Kuczynski et al. 2012) and the Phyloseq R package 1.5.21 (McMurdie and Holmes 2013). A set of Illumina reads was initially filtered and split according to the barcodes. Chimeric sequences were identified and excluded from the datasets using Usearch 6.1. A multi-step open-reference OTU picking workflow was performed within the QIIME system. OTUs were picked, assigning the reads to species groups based on $97 \%$ sequence similarity. All analyses and multivariate tests were performed using the OTUs relative abundances of the detected microbial community compositions on each sample. Each OTU with a relative abundance higher than $1 \%$ was considered as a key microbial community component of a given sample, and 
among these, the species-specific microbial community composition was defined as the set of OTUs present in all specimens of P. kanaky.

Alpha and Beta diversity analyses were performed using QIIME workflow and R software using Phyloseq (McMurdie and Holmes 2013) and Vegan R packages (Oksanen et al. 2019). All bar plots of abundance, diversity and distribution of all phyla were prepared with the Phyloseq R package. Weighted Unifrac distances were calculated between the microbial communities of the sponge specimens based on OTU presence and relative abundance (Lozupone et al. 2011). The same distance method was used for Beta diversity using the function Adonis using R software.

A heatmap based on a Discriminatory Analysis of Partial Least Square Regression PLSDA analysis was constructed using the online platform MetaboAnalyst (Xia and Wishart, 2016). We compared the 50 most important OTUs (Variables Important in Projection, VIP) on the basis of their occurrence in terms of number of reads distributed among all P. kanaky samples.

\section{Results}

A total of 256,458 sequences of 250 nucleotides on average were obtained and clustered into 2,829 OTUs at $97 \%$ similarity (Table 1). Rarefaction analyses showed that all $P$. kanaky samples similarly approached an asymptote near 6,000 sequence reads retrieved per amplicon describing more than $96 \%$ of the associated microbial communities, according to Good's coverage estimation (Supp Fig. 1). Beta diversity analysis using Permanova test revealed that the microbial community in $P$. kanaky presents no significant differences among sites $(\mathrm{F}=0.83$; $\mathrm{p}$-value $=0.74)$ and chromotypes $(\mathrm{F}=0.78$; $\mathrm{p}$-value $=0.76)$. The P. kanaky microbial community is composed of 14 formerly described Bacteria phyla and 1 Archaea lineage. Proteobacteria, Poribacteria and Chloroflexi are the predominant taxa constituting up to $70 \%$ of the bacterial community in all samples (Fig. 2A). At class level, $80 \%$ of OTUs were correctly assigned, however at the order level we found that $40 \%$ of the sequences could not be assigned to a known taxon.

Four abundant microbial classes represent between 60 and $80 \%$ of the OTUs recorded in the $P$. kanaky microbiome. They belong to the Deltaproteobacteria $(12-40 \%)$, to an unclassified class of Poribacteria (12 - 38\%), to the SAR202 cluster (7 - 22\%), and to the Gammaproteobacteria (4 - 10\%) (Fig. 2A-B). At the order level, only the order Entotheonellales (Deltaproteobacteria) could be identified among the 4 dominant classes recorded in the $P$. kanaky microbiome. However, other less abundant orders could be identified. They belong to the Acidimicrobiales (Class Acidimicrobia), 2-7\% of the OTUs recorded, and to the Caldilineales (Class Anaerolineae) with $0.5-5 \%$ of the total microbial community. Archaea also represents less than $2 \%$ on average of the total prokaryotic community associated with $P$. kanaky, and they are represented by two families of the class Thaumarchaeota: Nitrososphaeraceae and Cenarchaeaceae.

\section{[FIG 2]}

We performed intraspecific and interspecific comparisons of the microbial communities by generating and including in our datasets the microbiomes of another Homoscleromorpha and of three Demospongiae. This enabled us to compare the ribotypes detected and to characterize the species-specific community associated with $P$. kanaky specimens. Compared to other sponges analyzed, the largest difference (40\%) was found between all $P$. kanaky specimens and Amphimedon compressa, while the community associated with the Homoscleromorph Oscarella balibaloi appeared as the most similar with less than $20 \%$ divergence between both microbial communities. Two Chloroflexi OTUs were found in all sponge samples, one affiliated to the SAR202 cluster and the other one to the class TK17. 
The greatest divergences were observed when the abundance was not considered (unweighted). In this case, two groups corresponding to the Homoscleromorpha and Demospongiae were well separated (Fig. 2B). When the presence/absence of OTUs among samples were compared, such unweighted measures suggested that the microbial divergence between Homoscleromorpha samples is about $50 \%$, whereas it reaches $70 \%$ with the Demospongiae Amphimedon compressa, whose microbiome is mainly composed by Betaproteobacteria of the EC94 order (89\% of the OTUs). Since A. compressa is an HMA sponge species, it represents an exceptional contrasting pattern where phyla proposed to be LMA (Betaproteobacteria) and HMA (SAR202) indicators are coincidentally having a higher relative abundance. Searching for the common features of both Homoscleromorpha, we were able to detect some of the dominant OTUs of P. kanaky in O. balibaloi, one belonging to Poribacteria and two Chloroflexi: the SAR202 cluster and the Caldilineales order. Taken together, these three taxonomic groups, which are shared by both species, represent half of the total microbial community of the Oscarellidae.

The species-specific community of $P$. kanaky appears to be composed of 5 bacterial OTUs recorded in all studied specimens and representing about $10 \%$ of the total microbial community. These specific OTUs belong to Acidimicrobiales, an order in the phylum Actinobacteria, to two different SAR202 cluster in the Chloroflexi phylum, to the order Sva0725 in the Acidobacteria phylum, and to the family Endozoicomonadaceae in the Gammaproteobacteria class. Also observed in all P. kanaky samples, the Archaea genus Nitrosopumilus (Cenarchaeaceae) can be considered as a minor part of the species-specific community.

To complete our view of the species-specific community of P. kanaky, we created a heatmap showing the distribution of the 50 VIP OTUs among the various P. kanaky chromotypes. This representation indicates that 6 OTUs are shared by at least 6 P. kanaky specimens. They were assigned to Candidatus solibacter, to the family Methylococcaceae, to SAR202, HTCC2089 (Gammaproteobacteria) and to Candidatus Entotheonella. This candidate genus is actually represented by 6 different OTUs heterogeneously distributed in all P. kanaky specimens (Fig. 3), but because of the genetic differences between Enthotheonella OTUs (divergences greater than 3\%), this taxon was not originally detected as a part of the species-specific microbial community. However, even if not a single Entotheonella OTU could be detected in all specimens of $P$. kanaky, our previous electron microscopy observations of such morphotypes in all specimens and their larvae convinced us to assume this taxon as being part of the species-specific microbial community.

[FIG 3]

\section{Discussion}

The availability of high-throughput meta-barcoding approaches allows more accurate descriptions of the microbiomes associated with marine sponges. So far, only a few Homoscleromorpha have been investigated using such methods, although cytological observations of microbial morphotypes are often used as diagnostic traits to distinguish between species (Ereskovsky, Sanamyan and Vishnyakov 2009; Pérez et al. 2011; Ruiz et al. 2017). Previous work on the HMA Plakortis sp. has highlighted the occurrence of 8 bacterial phyla, among which the Chloroflexi and Acidobacteria that contain many spongespecific clusters (Taylor et al. 2007). Sharp et al. (2007) studied the vertical transmission of some original phylotypes of Proteobacteria, Actinobacteria, Nitrospira and Cloroflexi in Corticium sp.; among these phyla, the closest previously known bacterial relatives were sulfur-oxidizing Gammaproteobacteria, nitrogen-fixing Rhizobiales and Actinobacteria, with the latter phylum being recognized for its ability to produce bioactive compounds (Sharp et al. 2007). 
Most of the species-specific community associated with $P$. kanaky can be classified among Proteobacteria and Poribacteria, but Actinobacteria and Chloroflexi are also recorded in abundance. Proteobacteria is mostly represented by Delta- Gamma- and Alphaproteobacteria. Four orders dominate, Entotheonellales (Deltaproteobacteria with 11 - $38 \%$ of relative abundance), an unidentified Poribacteria (12 - 38\%), a second unidentified order belonging to the class SAR202 (Chloroflexi), and Acidimicrobiales (Actinobacteria with $3-7 \%$ of relative abundance).

Poribacteria have been associated with polyketides and methyl-branched fatty acid production (Hochmuth et al. 2010), suggesting also their involvement in the production of secondary metabolites. Three OTUs are related to the Chloroflexi class SAR202 and account for half of the total specific community. SAR202 has also a good number of representatives which have been recorded in soil, freshwater, marine, wastewater, and subsurface environments (Morris et al. 2004). While the global bacterial abundance generally decreases with ocean depth, the absolute abundance of SAR202 increases from the subsurface to the meso- and bathypelagic waters (Varela et al. 2008). This distribution pattern indicates that SAR202 is well adapted to the environmental conditions of the dark ocean, such as the small dark cavities where P. kanaky dwells. Using MICRO-FISH, Varela et al. (2008) found that uptake of L-Asp by SAR202 cells remains stable throughout the water column, suggesting that this cluster may play a key role in lower-surface and deep-ocean biogeochemistry. The order Acidimicrobiales contains mesophilic and moderate thermophilic species, of which all members are obligatory acidophilic and are found in iron-, sulfur- or mineral-sulfide rich environments. Species within this order are capable of ferrous iron and sulfur oxidation and ferric iron reduction (Clark and Norris 1996; Stackebrandt, Rainey and Ward-Rainey 1997; Johnson et al. 2009). Taylor et al (2007) found several sponge-specific clusters in tropical sponges such as Agelas dilatata, Discodermia dissoluta, Plakortis sp. and Xestospongia muta from the Caribbean Sea, $X$. testudinaria from Indonesia and Dysidea sp. from the Southern China Sea.

Entotheonella sp., first identified in Tetractinellid sponges (Schmidt et al. 2000; Schirmer et al. 2005; Brück et al. 2008), is a bacterial group known for being a unique source of bioactive molecules (Bewley, Holland and Faulkner 1996; Jaspars and Challis 2014; Wilson et al. 2014). Widely distributed throughout the ocean, this phylotype is generally considered to be a free-living planktonic bacterium, acquired by sponges from the environment (Wilson et al. 2014). However, the cytological description of P. kanaky reported the predominance of a filamentous Entotheonella-like bacteria in all four chromotypes of $P$. kanaky as well as in their embryos (Ruiz et al. 2015). The present study confirms the occurrence of Entotheonella, and the great novelty of this first record in Homoscleromorph sponges also provides the first clues to its vertical transmission. In the species-specific community of P. kanaky, Entothenonella is represented by 12 different OTUs with $97 \%$ similarity. However, we believe that small genetic divergences in the hypervariable V5 - V6 region may explain the assignment of various OTUs to Candidatus Entotheonella sp. Considering the large specialized biosynthetic repertory reported for Entotheonella, its close association to P. kanaky likely confers great properties of adaptation to the whole sponge holobiont. Finally, regarding archaeal groups detected in P. kanaky, they had been reported with steady detection and low abundances in the microbiomes of most sponge species surveyed so far (Thomas et al. 2016) with only few reported exceptions were these groups are predominant (Turque et al. 2010; Jackson et al. 2013; Garcia-Bonilla et al. 2019). Among them, the occurring OTUs assigned to Thaumarchaeota are associated with genera playing essential metabolic activities such as ammonia oxidation, which is one of the first reactions carried out to achieve nitrification (Steger et al. 2008). Members related to the archaeal clade of the Nitrososphaera- 
Nitrosopumilus cluster (Stieglmeier et al. 2014) could be the globulous prokaryotic form described in P. kanaky adults and larvae (Ruiz et al. 2015), a morphotype never before observed in sponges. This is a possibility still to be confirmed and requiring further investigation. It must be noted that the use of more specific molecular markers might reveal a much higher diversity of symbiotic Archaea in sponges, particularly in those living in extreme environments, and might thus highlight other putative adaptive capabilities.

The microbial community associated to Plakina kanaky has no significant differences among chromotypes and/or sites. It is likely that this community is transferred from parents to offspring, while other OTUs can be acquired from the environment. Both types of acquisition are key processes which may improve the adaptive capabilities of a holobiont living in constraining environments such as underwater caves. The microbial diversity associated with Homoscleromorpha may thus partly explain the ecological success of this poorly known sponge group in dark and oligotrophic environments. This preliminary study may thus serve as a baseline for further research on the adaptative capabilities of Homoscleromorpha.

\section{Acknowledgments}

We would like to thank EcosNord and Colciencias for financial support though bilateral research cooperation and mobility grants from 2012-2014 and 2015-2017. Funding was provided by the CNRS LIA MARRIO, TOTAL Foundation. The authors are grateful to the Institut de Recherche pour le Développement (IRD) for providing diving facilities in New Caledonia, and to Virginie Baldy (IMBE) for her contribution to the field work. We thank Eric JC Gálvez, Silke Kahl and Iris Plumeier, HZI, Braunschweig, for technical advice on amplicon preparation and sequencing, and to Dr. Erika García-Bonilla, Microbiomas Foundation, and Prof. Andrés Pinzón Velasco, Universidad Nacional de Colombia, for kindly supporting bioinformatic resources and analyses.

\section{References}

Bewley CA, Holland ND, Faulkner DJ. Two classes of metabolites from Theonella swinhoei are localized in distinct populations of bacterial symbionts. Experientia 1996;52:716-722.

Bohorquez LC, Delgado-Serrano L, López G et al. In-depth characterization via complementing culture-independent approaches of the microbial community in an acidic hot spring of the Colombian Andes. Microbial Ecology 2012;63:103-115.

Boury-Esnault N, Muricy G, Gallissian MF. Sponges without skeleton: A new Mediterranean genus of Homoscleromopha (Porifera, Demospongiae). Ophelia 1995; 1:25-43.

Brück WM, Sennett SH, Pomponi SA et al. Identification of the bacterial symbiont Entotheonella sp. in the mesohyl of the marine sponge Discodermia sp. The ISME journal 2008;2:335-339.

Clark DA, Norris PR. Acidimicrobium ferrooxidans gen. nov., sp. nov.: mixed-culture ferrous iron oxidation with Sulfobacillus species. Microbiology 1996;142:785-790.

Easson CG, Thacker RW. Phylogenetic signal in the community structure of host-specific microbiomes of tropical marine sponges. Frontiers in microbiology 2014;5:532.

Ereskovsky AV, Sanamyan K, Vishnyakov AE. A new species of the genus Oscarella (Porifera: Homscleromorpha/ Plakinidae) from the North-West Pacific. Cahier de Biologie Marine 2009;50:369-81.

Fieseler L, Horn $\mathrm{M}$, Wagner $\mathrm{M}$ et al. Discovery of the novel candidate Phylum "Poribacteria" in marine sponges. Applied and Environmental Microbiology 2004;70:3724-32. 
García-Bonilla, E., Brandão, P. F., Pérez, T., \& Junca, H. Stable and enriched Cenarchaeum symbiosum and uncultured Betaproteobacteria HF1 in the microbiome of the Mediterranean sponge Haliclona fulva (Demospongiae: Haplosclerida). Microbial ecology, 2019;77(1), 25-36.

Gloeckner V, Hentschel U, Ereskovsky AV et al. Unique and species-specific microbial communities in Oscarella lobularis and other Mediterranean Oscarella species (Porifera: Homoscleromorpha). Marine Biology 2013;160:781-91.

Hardoim CCP, Esteves AIS, Pires FR et al. Phylogenetically and spatially close marine sponges harbour divergent bacterial communities. Harder $\mathrm{T}$ (ed.). PLoS One 2012;7:e53029.

Hentschel U, Hopke J, Horn $\mathrm{M}$ et al. Molecular evidence for a uniform microbial community in sponges from different oceans. Applied and Environmental Microbiology 2002;68:4431-40.

Hentschel U, Piel J, Degnan SM et al. Genomic insights into the marine sponge microbiome. Nature Reviews Microbiology 2012;10:641-654.

Hochmuth T, Niederkrüger $\mathrm{H}$, Gernert $\mathrm{C}$ et al. Linking chemical and microbial diversity in marine sponges: possible role for Poribacteria as producers of methyl-branched fatty acids. ChemBioChem 2010;11:2572-8.

Jaspars M, Challis GA talented genus. Nature 2014;506:38-9.

Jackson, S. A., Flemer, B., McCann, A., Kennedy, J., Morrissey, J. P., O’Gara, F., \& Dobson, A. D. (2013). Archaea appear to dominate the microbiome of Inflatella pellicula deep sea sponges. PloS One 2013;8(12), e84438.

Johnson DB, Bacelar-Nicolau P, Okibe N et al. Ferrimicrobium acidiphilum gen. nov., sp. nov. and Ferrithrix thermotolerans gen. nov., sp. nov.: heterotrophic, iron-oxidizing, extremely acidophilic actinobacteria. International Journal of Systematic and Evolutionary Microbiology 2009;59:1082-9.

Lozupone C, Lladser M, Knights D et al. UniFrac: an effective distance metric for microbial community comparison. The ISME Journal 2011;5:169-72.

Kuczynski J, Stombaugh J, Walters WA et al. Using QIIME to analyze 16S rRNA gene sequences from microbial communities. Current protocols in microbiology 2012;120.

McMurdie PJ, Holmes S. Phyloseq: An R package for reproducible interactive analysis and graphics of microbiome census data. PLoS One 2013;8:e61217.

Milici M, Tomasch J, Wos-Oxley ML et al. Low diversity of planktonic bacteria in the tropical ocean. Scientific reports 2016;6:19054.

Morris RM, Rappé M, Urbach E et al. Prevalence of the Chloroflexi-Related SAR202 Bacterioplankton Cluster throughout the Mesopelagic Zone and Deep Ocean. Appl Environ Microbiol 2004;70:2836, 2836-42.

Muricy G, Boury-Esnault N, Bézac C et al. Cytological evidence for cryptic speciation in Mediterranean Oscarella species (Porifera, Homoscleromorpha). Canadian Journal of Zoology 1996;74:881-96.

Muricy G, Bézac C, Gallissian MF et al. Anatomy, cytology and symbiotic bacteria of four Mediterranean species of Plakina Schulze, 1880 (Demospongiae, Homosclerophorida). Journal of ANtural History 1999;33:159-76.

Oksanen J, Blanchet G, Friendly et al. Vegan: community ecology package. R package version 2.5-6. 2019. https://CRAN.R-project.org/package=vegan

Pérez T, Ivanišević J, Dubois $M$ et al. Oscarella balibaloi, a new sponge species (Homoscleromorpha: Plakinidae) from the Western Mediterranean Sea: cytological description, reproductive cycle and ecology: $O$. balibaloi: description, reproductive cycle and ecology. Marine Ecology 2011;32:174-87. 
Pérez T, Ruiz C. Description of the first Caribbean Oscarellidae (Porifera: Homoscleromorpha). Zootaxa 2018;4369:501-514

Pita L, Rix L, Slaby BM et al. The sponge holobiont in a changing ocean: from microbes to ecosystems. Microbiome 2018;6:46

Reveillaud J, Maignien L, Eren MA et al. Host-specificity among abundant and rare taxa in the sponge microbiome. The ISME Journal 2014;8:1198-209.

Ruiz C, Ivanišević J, Chevaldonné P et al. Integrative taxonomic description of Plakina kanaky, a new polychromatic sponge species from New Caledonia (Porifera: Homoscleromorpha). Marine Ecology 2015;36:1129-43.

Ruiz C, Muricy G, Lage A et al. Descriptions of new sponge species and genus, including aspiculate Plakinidae, overturn the Homoscleromorpha classification. Zoological Journal of the Linnean Society 2017;179:707-24.

Schirmer A, Gadkari R, Reeves CD et al. Metagenomic analysis reveals diverse polyketide synthase gene clusters in microorganisms associated with the marine sponge Discodermia dissoluta. Applied Environmental Microbiology 2005;71:4840-9.

Schmidt EW, Obraztsova AY, Davidson SK et al. Identification of the anifungal peptidecontaining symbiont of the marine sponge Theonella swinhoei as a novel deltaProteobacterim, “Candidatus Entotheonella palauensis.” Marine Biology 2000;96977.

Schmitt S, Tsai P, Bell J et al. Assessing the complex sponge microbiota: core, variable and species-specific bacterial communities in marine sponges. The ISME Journal 2011;6:564-76.

Sharp KH, Eam B, Faulkner DJ et al. Vertical transmission of diverse microbes in the tropical sponge Corticium sp. Applied and Environmental Microbiology 2007;73:6229.

Stackebrandt E, Rainey FA, Ward-Rainey NL. Proposal for a new hierarchic classification system, Actinobacteria classis nov. International Journal of Systematic and Evolutionary Microbiology 1997;47:479-91.

Steger D, Ettinger-Epstein P, Whalan S et al. Diversity and mode of transmission of ammonia-oxidizing archaea in marine sponges. Environmental Microbiology 2008;10:1087-94.

Stieglmeier M, Klingl A, Alves RJ et al. Nitrososphaera viennensis gen. nov., sp. nov., an aerobic and mesophilic, ammonia-oxidizing archaeon from soil and a member of the archaeal phylum Thaumarchaeota. International Journal of Systematic and Evolutionary Microbiology 2014;64:2738.

Taylor MW, Radax R, Steger D et al. Sponge-Associated Microorganisms: Evolution, Ecology, and Biotechnological Potential. Microbiology and Molecular Biology Reviews. Academic press, 2007,71:295-347.

Thacker RW, Freeman CJ. Sponge-Microbe Symbioses. In: Becerro MA, Maldonado M, Turon X (eds.) Advances in Marine Biology. Vol 62. Elsevier, 2012, 57-111.

Thomas T, Rusch D, DeMaere MZ et al. Functional genomic signatures of sponge bacteria reveal unique and shared features of symbiosis. The ISME journal 2010;4:1557-1567.

Thomas T, Moitinho-Silva L, Lurgi M et al. Diversity, structure and convergent evolution of the global sponge microbiome. Nature Communications 2016;7:11870.

Turque AS, Batista D, Silveira CB et al. Environmental Shaping of Sponge Associated Archaeal Communities. PLoS One 2010;5:e15774.

Uriz MJ, Agell G, Blanquer A et al. Endosymbiotic Calcifying Bacteria: A New Cue to the Origin of Calcification in Metazoa? Evolution 2012;66:2993-9.

Vacelet J. Etude en microscopie électronique de l'association entre bactéries et spongiaires du genre Verongia (Dyctioceratida). Journal de Microscopie et de Biologie Cellulaire 1975;23:271-88. 
Varela MM, Van Aken HM, Sintes E et al. Latitudinal trends of Crenarchaeota and Bacteria in the meso- and bathypelagic water masses of the Eastern North Atlantic. Environmental Microbiology 2008;10:110-24.

Van Soest RWM, Boury-Esnault N, Hooper JNA et al. World Porifera Database http : http://www.marinespecies.org/porifera/index.php. Accessed 15 Fev 2020

Villegas-Plazas, M., Wos-Oxley, M. L., Sanchez, J. A., Pieper, D. H., Thomas, O. P., \& Junca, H. Variations in microbial diversity and metabolite profiles of the tropical marine sponge Xestospongia muta with season and depth. Microbial ecology 2019;78(1), 243-256.

Webster NS, Taylor MW, Behnam F et al. Deep sequencing reveals exceptional diversity and modes of transmission for bacterial sponge symbionts. Environmental Microbiology 2010;12:2070-82.

Webster NS, Taylor MW. Marine sponges and their microbial symbionts: love and other relationships Environmental Microbiology 2011;14:335-46.

Webster NS, Thomas T. The sponge hologenome. MBio 2016;7:e00135-16.

Wilson MC, Mori T, Rückert C et al. An environmental bacterial taxon with a large and distinct metabolic repertoire. Nature 2014;506:58-62.

Xia J, Wishart DS. Using MetaboAnalyst 3.0 for Comprehensive Metabolomics Data Analysis. Current Protocols in Bioinformatics 2016:14-10. 


\section{Figures}

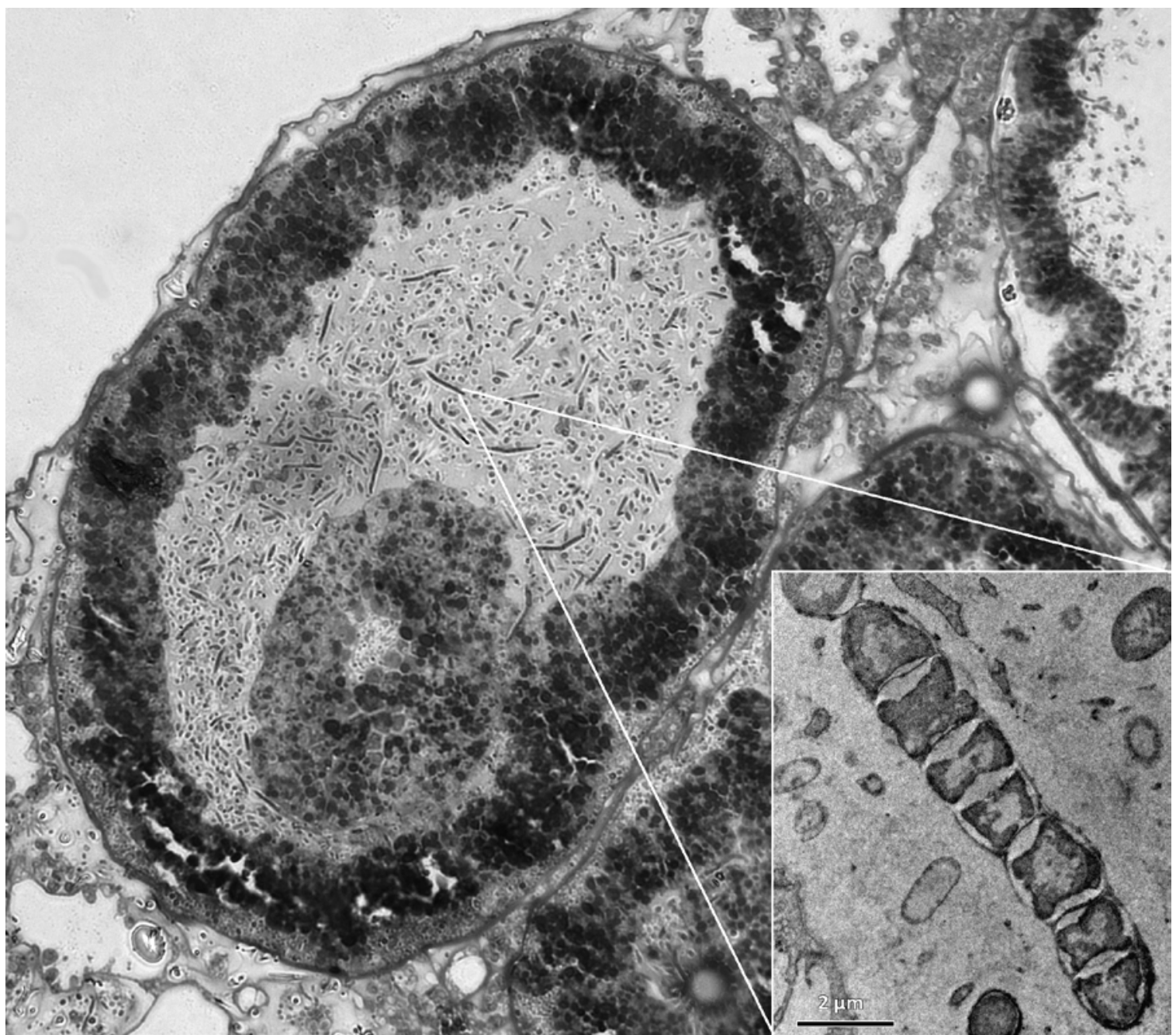

Figure 1. Coeloblastula of Plakina kanaky with a detailed view of the filamentous morphotype associated with Candidatus Entotheonella sp., found in both the adult and the larvae of P. kanaky. 
(A)

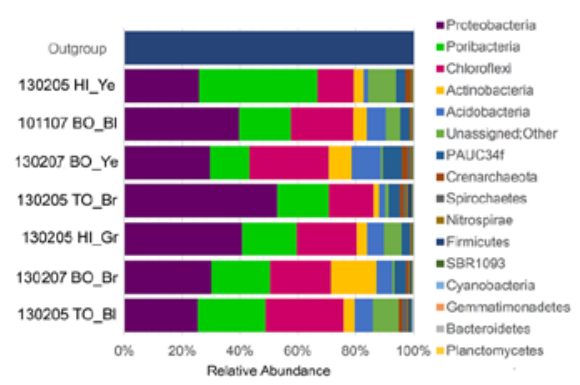

(C)

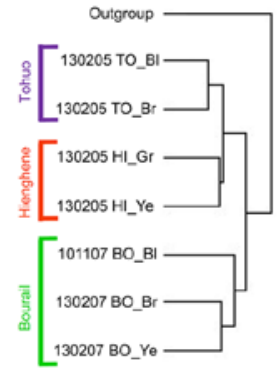

(B)

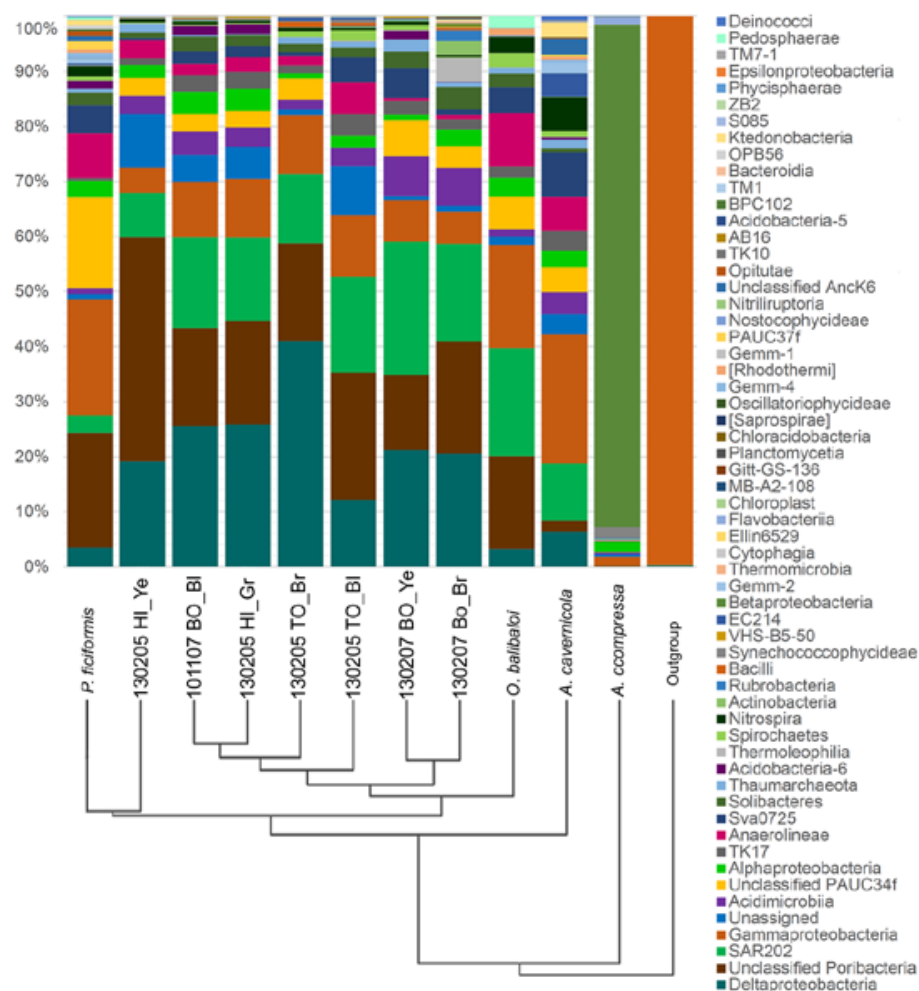

Figure 2. (A) Occurrence of all phyla inferred from 16S amplicon Illumina reads with an average of 8504 sequences per specimen. (B) Relative class abundance inferred from 16S amplicon Illumina reads with an average of 9820 sequences per specimen and a hierarchical clustering through a weighted UniFrac matrix. (C) Similarity of the samples throughout the Bray Curtis method according to the number of shared OTUs.

Plakina kanaky specimen's abbreviations: TO, Touho. BO, Bourail. HE, Hienghène. Bl, bleu. Br, Brick-Red. Ye, Yellow. Gr, Green. 


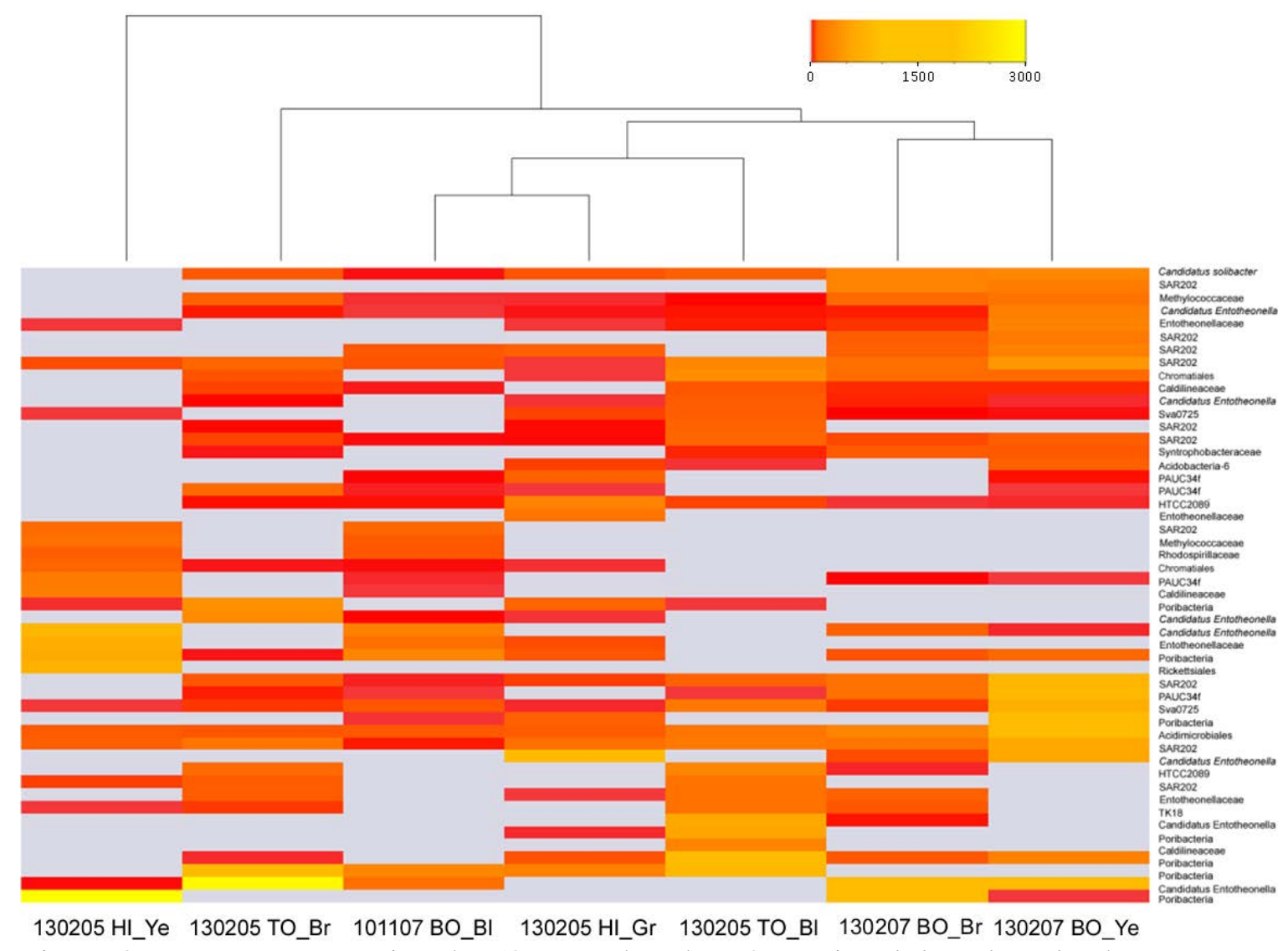

Figure 3. Heatmap comparing the 50 most abundant OTUs in Plakina kanaky chromotypes, and dendrogram indicating the intra- and interspecies relationships (top). Heat colours indicate number of reads per taxa, from zero reads (grey) to 3000 reads (yellow). Only the OTUs which are shared by at least 6 chromotypes are marked with black circles and listed in order of appearance (from top to bottom) on the heatmap. Red circles indicate the OTUs assigned to Candidatus Entotheonella.

Plakina kanaky specimen's abbreviations: TO, Touho. BO, Bourail. HE, Hienghène. Bl, bleu. Br, Brick-Red. Ye, Yellow. Gr, Green.

Table 1. Individuals and collection sites of the studied specimens (11) with the number of reads and OTUs (97 \% similarity) per specimen. NC: New Caledonia; FR: France.

\begin{tabular}{|c|c|c|c|c|c|}
\hline Sponge species & sample code & Chromo type & Collection site & $\begin{array}{l}\# \\
\text { Reads } \\
\end{array}$ & $\begin{array}{l}\# \\
\text { OTUs } \\
\end{array}$ \\
\hline Plakina kanaky & 130207-BO_Ye & Yellow (Ye) & Bourail (BO) & 17024 & 852 \\
\hline P. kanaky & 130207BO_Br & Brick-Red (Br) & Bourail (BO) & 12913 & 915 \\
\hline P. kanaky & 101107BO_Bl & Blue (Bl) & Bourail (BO) & 5818 & 376 \\
\hline P. kanaky & 130205TO_Br & Brick-Red (Br) & Touho (TO) & 10470 & 520 \\
\hline P. kanaky & 130205TO_Bl & Blue (Bl) & Touho (TO) & 12713 & 556 \\
\hline P. kanaky & 130205HI_Ye & Yellow (Ye) & Hienghène (HI) & 13351 & 413 \\
\hline P. kanaky & 130205HI_Gr & Green (Gr) & Hienghène (HI) & 7201 & 409 \\
\hline Amphimedon compressa & ACM.C3 & NA & La Martinique & 13203 & 298 \\
\hline Aplysina cavernicola & FA.M5 & NA & Marseille (FR) & 38489 & 919 \\
\hline Petrosia ficiformis & PF.M5 & NA & Marseille (FR) & 35031 & 737 \\
\hline Oscarella balibaloi & OB.M7 & NA & Marseille (FR) & 24395 & 440 \\
\hline
\end{tabular}




\section{Supporting Infomation}

Supplementary figure 1. (A) Chao1 indicator. This plot is showing the coverage of sequencing and the richness of all samples. (B) Rank abundance plot of OTUs and sequence accumulation on each specimen observed at $97 \%$ similarity in datasets. Plakina kanaky specimen's abbreviations: TO, Touho. BO, Bourail. HE, Hienghène. Bl, bleu. Br, Brick-Red. Ye, Yellow. Gr, Green. 